\title{
Ciprofloxacin and Metronidazole Allergy- A Case Report
}

\author{
Rashi Bahuguna ${ }^{1}$, Devesh Joshi ${ }^{1}$, Madhulata Rana \\ ${ }^{1}$ Pharm.D. Student, Department of Pharmacy Practice, \\ Shri Guru Ram Rai Institute of Technology \& Science, Dehradun, Uttarakhand, India \\ ${ }^{2}$ Professor, Department of Surgery,
} Shri Guru Ram Rai Institute of Medical and Health Sciences, Dehradun, Uttarakhand, India

Corresponding Author: Rashi Bahuguna

\section{ABSTRACT}

Fluoroquinolones are well-tolerated antibiotics widely used for treating infections. According to the literature, ciprofloxacin is mostly involved in Drug-induced hypersensitivity reactions. The various reactions that are reported in various case reports due to ciprofloxacin include Steven Johnson syndrome, eczema, erythroderma, maculopapular rashes. Metronidazole is a 5nitroimidazole compound introduced in 1959 to treat Trichomonas vaginalis infections. Ciprofloxacin and Metronidazole hypersensitivity is not very frequent it is usually well tolerated but allergic reactions to these drugs occur due to their increased use either alone or in combination. An 83-year-old female was admitted to the private ward of surgery at Shri Mahant Indiresh hospital with chief complaints of abdominal pain and chronic constipation as the patient was not passing stools for 10 days. The patient was diagnosed with Subacute intestinal obstruction (SAIO) based on various laboratory findings and the symptomatic treatment was given treatment. Hypersensitivity reactions can be of two types immediate that occurs within few hours of drug administration and delayed that occurs within 24-48 hours of drug administration. Here in this case the person developed vomiting immediately after few hours of Ciprofloxacin administration so it is an immediate IgE mediated anaphylactic reaction. Metronidazole is causing Type 4 Delayed hypersensitivity reaction in this patient as rashes and itching developed the next day after administration of metronidazole drug. Healthcare professionals should maintain the record of a medication history of the patient to
\end{abstract}

identify any drug allergy so that it can be avoided in the future and in case of any ADR it should be reported. The patient should be advised to go for a sensitivity test to check which drug he/ she is allergic to and should avoid taking that medication. The patient should tell his/ her history of drug allergy to the doctor so that doctor doesn't prescribe that medication.

Keywords: CBC-Complete Blood Count, RFTRenal Function tests, LFT-Liver function tests, Hb-Hemoglobin, SGOT-Serum Glutamic oxaloacetic transaminases, ALP-Alkaline phosphatase, MCH-mean corpuscular Hemoglobin, MCHC-Mean corpuscular hemoglobin concentration, RBC-Red Blood Cells, SAIO-Subacute intestinal obstruction, USG- Ultrasound.

\section{INTRODUCTION}

Fluoroquinolones are well-tolerated antibiotics widely used for treating infections ${ }^{1}$. The most widely used antibiotics among them are ciprofloxacin, moxifloxacin, and levofloxacin ${ }^{2}$. The most frequent adverse events that are associated with fluoroquinolones are pain in the abdomen, depression, headache, restlessness, diarrhea, nausea, and insomnia ${ }^{3}$. Increased use of fluoroquinolones has to lead to associated hypersensitivity reactions ${ }^{4}$. Hypersensitivity reactions can be of two types immediate that occurs within few hours of drug administration and delayed that occurs within 24-48 hours of drug administration ${ }^{\mathbf{5}}$. 
Fluoroquinolone allergy can be of any type but usually is an immediate hypersensitivity reaction. It is $\operatorname{IgE}$ mediated anaphylactic immediate hypersensitivity reaction ${ }^{6-11}$.

According to the literature, ciprofloxacin is mostly involved in Druginduced hypersensitivity reactions. The various reactions that are reported in various case reports due to ciprofloxacin include Steven Johnson syndrome, eczema, erythroderma, maculopapular rashes ${ }^{\mathbf{1 2}}$, erythema multiforme, demarcated erythematous plaques, vesicular and bullous lesions, and ciprofloxacin-induced thrombocytopenia ${ }^{\text {13-16. }}$.

Skin tests are considered for determining the type of drug allergy the patient is experiencing but due to histamine release, it can show false positive results ${ }^{17}$. In vitro, radioimmunoassay and basophil activation tests are also used for the diagnosis of drug-induced hypersensitivity reaction. Delayed types of Hypersensitivity reactions to fluoroquinolones are also observed in some cases and these reactions are $\mathrm{T}$ cell-mediated reactions. The reactions due to fluoroquinolones can be mild, moderate, or severe and it is difficult to confirm the drug causing hypersensitivity reaction ${ }^{4}$.

Metronidazole is a 5-nitroimidazole compound introduced in 1959 to treat Trichomonas vaginalis infections and is also used to treat parasitic infections, alone or in combination with other antibiotics. Metronidazole hypersensitivity is not very frequent it is usually well tolerated but the common adverse reactions are gastrointestinal symptoms, hematological alterations, central nervous system disorders, and, rarely, drug rashes ${ }^{18}$, 19

Hypersensitivity to metronidazole is due to increased use of the drug alone or in combination with other drugs to treat amebiasis and anaerobe infections. Studies showed that metronidazole-induced hypersensitivity reaction can be of both immediate and delayed type ${ }^{\mathbf{2 0}}$. The reported hypersensitivity reactions to metronidazole are allergic contact dermatitis ${ }^{\mathbf{2 1}}$, fixeddrug eruptions ${ }^{22}$, systemic reactions ${ }^{23}$, respiratory disorders $^{\mathbf{2 4 , 2 5}}$, anaphylactic reactions ${ }^{\mathbf{1 8}}$, Stevens-Johnson syndrome/toxic epidermal necrolysis ${ }^{\mathbf{2 6}}$, acute generalized exanthematous pustulosis ${ }^{27}$, and serum sickness reactions ${ }^{28}$.

A study also reported a rare delayed systemic hypersensitivity reaction characterized by angioedema and widespread erythematous maculopapular rashes due to metronidazole administration without any topical sensitization and patch test confirmation ${ }^{29}$.

\section{CASE REPORT}

An 83-year-old female was admitted to the private ward of surgery at Shri Mahant Indiresh hospital with chief complaints of abdominal pain and chronic constipation as the patient was not passing stools for 10 days. Ten days ago, the patient seemed to be in good health. She was having stomach pains and wasn't passing stools. The pain was sudden in onset and was spasmodic. The following laboratory tests were performed

\section{Complete Blood count (CBC)}

\begin{tabular}{|c|l|l|}
\hline i. & Hb & $10.9 \mathrm{mg} / \mathrm{dl}(\mathrm{L})$ \\
\hline ii. & Neutrophils & $74 \%(\mathrm{H})$ \\
\hline iii. & Lymphocytes & $20 \%(\mathrm{~L})$ \\
\hline iv. & Monocytes & $05 \%(\mathrm{~L})$ \\
\hline v. & RBC & $3.38 \mathrm{million} /$ cumm $(\mathrm{L})$ \\
\hline vi. & PCV & $31 \%(\mathrm{~L})$ \\
\hline vii. & MCH & $32.2 \mathrm{Pg}(\mathrm{H})$ \\
\hline viii. & MCHC & $35 \mathrm{~g} / \mathrm{dl}(\mathrm{H})$ \\
\hline
\end{tabular}

Liver Function tests (LFT)

\begin{tabular}{|l|l|}
\hline SGOT (AST) & $48 \mathrm{U} / \mathrm{L}(\mathrm{H})$ \\
\hline SGPT (ALT) & $53 \mathrm{U} / \mathrm{L}(\mathrm{H})$ \\
\hline
\end{tabular}

Renal Function Tests (RFT)

\begin{tabular}{|l|l|}
\hline Serum Urea & $74 \mathrm{mg} / \mathrm{dl}(\mathrm{H})$ \\
\hline Serum Creatinine & $1.3 \mathrm{mg} / \mathrm{dl}(\mathrm{H})$ \\
\hline Uric acid & $69 \mathrm{mg} / \mathrm{dl}(\mathrm{H})$ \\
\hline Cholesterol & $100 \mathrm{mg} / \mathrm{dl}(\mathrm{L})$ \\
\hline
\end{tabular}

Ultrasound (USG): Ultrasound was indicative of small sized bilateral kidneys with left renal simple cyst.

The patient was diagnosed with Subacute intestinal obstruction (SAIO) as she was having increased levels of serum urea, serum creatinine and uric acid which is 
indicative of waste accumulation in the body provided she is also diagnosed with small-sized bilateral kidneys due to which the kidney is not filtering the body waste.

The treatment to treat intestinal obstruction was started hence patients was injected Injection Metronidazole to treat constipation and Injection Ciprofloxacin to treat any kind of infection in the kidneys. Soon after the Ciprofloxacin was administered within a few hours patient started vomiting while the next day patient also developed rashes and itching all over the body. Both the drugs were stopped immediately after the symptoms appeared as the reactions occurred due to drug administration and the symptoms were relieved after few hours. While other drugs like Syrup Cremaffin plus were continued to correct bowel movement, Injection Diclofenac and paracetamol combination, and to treat stomach pain the suppository PC enema to treat constipation were continued. Some other drugs were also continued for other co-morbid conditions.

\section{DISCUSSION}

1. There are two types of Hypersensitivity reactions: Immediate hypersensitivity reaction: It is the type of reaction which occurs immediately within few seconds minutes or hours after the drug administration. This hypersensitivity reaction is mediated by Humoral antibodies that are B cells. Example: Anaphylactic hypersensitivity reaction $^{30}$.

2. Delayed hypersensitivity reaction: This type of reaction occurs slowly that is within 24 to 48 hours after drug administration. This reaction is mediated by the cellular response that is $\mathrm{T}$ cells ${ }^{30}$.

\section{Ciprofloxacin Induced Hypersensitivity Reaction}

The mechanism of a quinolone allergy has been described mainly by two pathways supported by the Coombs and Gell classification:
1. IgE-mediated IR or type I anaphylactic reaction: It is the type of immediate hypersensitivity reaction and is IgE mediated anaphylactic reaction. It is characterized by mast-cell degranulation. Examples of allergies include Urticaria, anaphylaxis, asthma, rhinitis, and angioedema ${ }^{31}$.

2. T-cell-mediated or type IV Delayed Hypersensitivity reaction: It is the type Delayed hypersensitivity reaction and is CD8+ and CD4+ cell-mediated. Examples include contact eczema, maculopapular exanthema, bullous exanthema, Steven - Johnson syndrome Toxic epidermal necrolysis (SJS-TEN), fixed drug eruption (FDE), acute generalized exanthematous pustulosis (AGEP), and delayed urticaria ${ }^{31}$.

\section{Anaphylactic (Type 1) Hypersensitivity Reaction Due To Metronidazole \\ Administration}

Patient developed vomiting immediately after few hours of Ciprofloxacin administration so it is an immediate IgE mediated anaphylactic reaction.

1. Sensitization: When the antigen which is ciprofloxacin in this case comes in contact with the host body it stimulates the B-cells containing IgE antibodies ${ }^{32}$.

2. In response to sensitization plasma cells are activated and release the IgE antibodies from the surface ${ }^{32,33}$.

3. The released $\operatorname{IgE}$ antibodies bind firmly to FC receptors of the basophil-mast cell; this damages the surface of the cell membrane leading to sodium and water influx which ultimately causes degranulation of mast cell ${ }^{\mathbf{3 2}, 33}$.

4. The granules released after lysis of mast cell releases enzymes and inflammatory mediators like vasoactive peptide (VIP), leukotrienes, neutrophils, eosinophils, and platelet-activating factors etc ${ }^{32,33}$. (Figure- 1) 


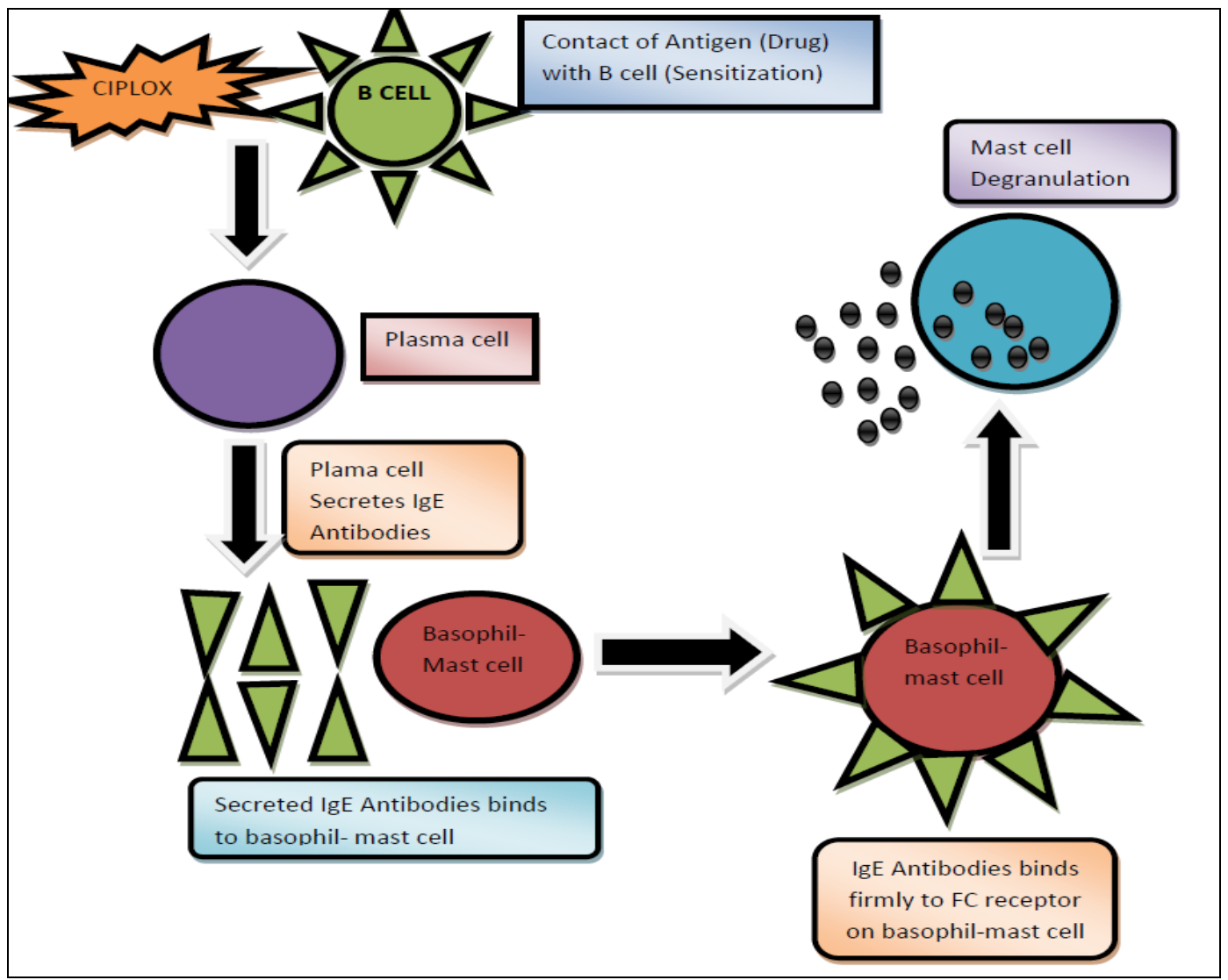

Figure 1: Type-1 Anaphylactic Hypersensitivity Reaction In Patient Due To Ciprofloxacin Drug

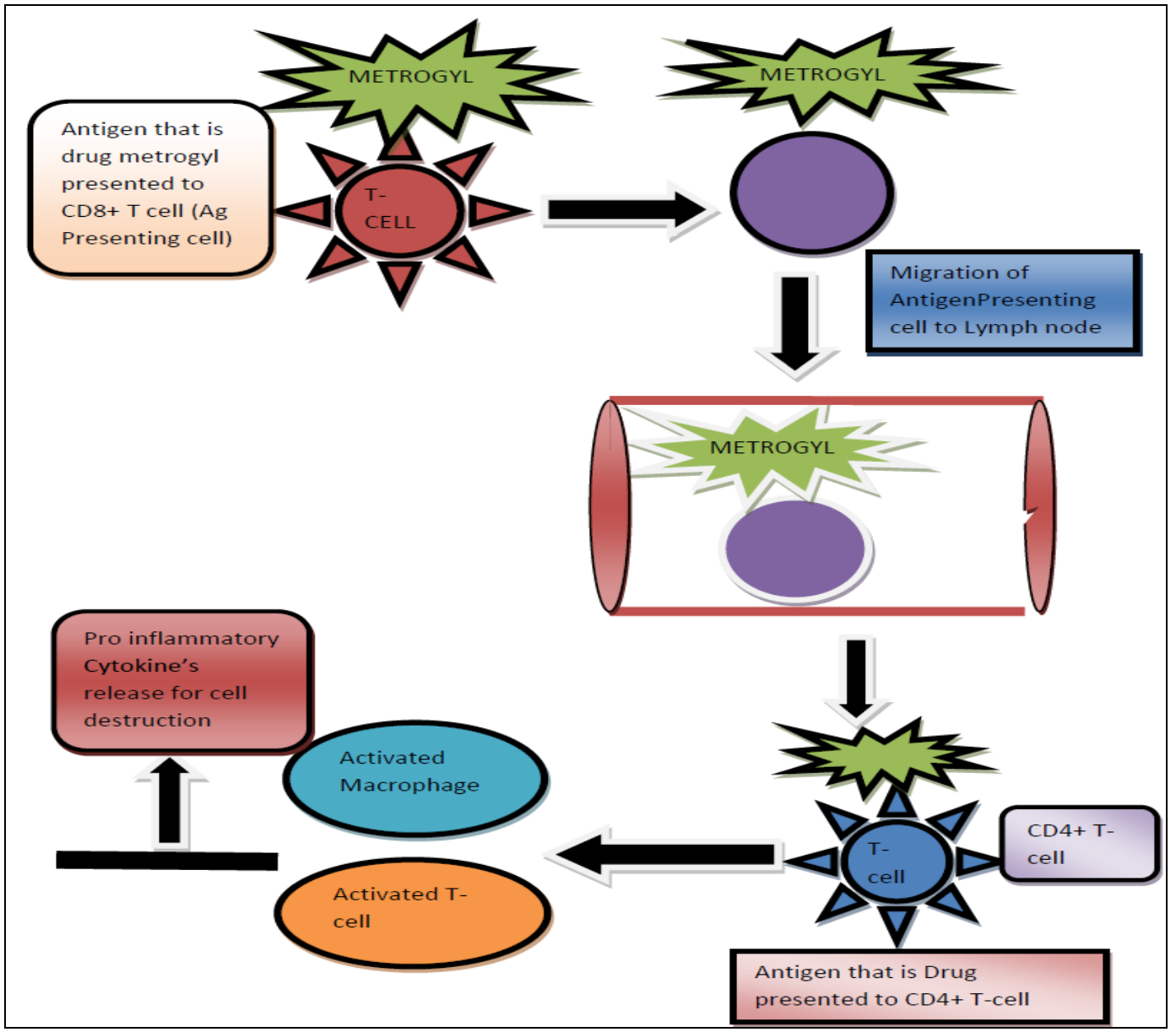

Figure: 2: Type-D Delayed Hypersensitivity Reaction In Patient Due To Metronidazole Drug 
Type-4 Delayed Hypersensitivity Reaction Due To Metronidazole Drug Administration

Metrogyl (Metronidazole) is causing Type 4 Delayed hypersensitivity reaction in this patient as rashes and itching developed the next day after administration of metronidazole drug.

1. Antigen (Metrogyl) is presented to the antigen-presenting cell that is $\mathrm{CD} 8+\mathrm{T}$ cell when the drug enters the body ${ }^{32,33}$.

2. The antigen-presenting cell that is CD8+ T-cell then moves to lymph node and presents the antigen to Helper CD4+ Tcell $^{32,33}$.

3. The CD4+ T-cell produces cytokines after antigen is presented to it which stimulates T-cell proliferation with activation of macrophages ${ }^{32,33}$.

4. The activated T-cells and macrophages release inflammatory mediators which are responsible for cell destruction and allergic reactions ${ }^{\mathbf{3 2}, 33}$.(figure-2)

\section{CONCLUSION}

There is no specific treatment of hypersensitivity reaction so prevention is the best measure. The patient should be advised to go for a sensitivity test to check which drug he/she is allergic to and should avoid taking that medication. The patient should tell his/her history of drug allergy to the doctor so that doctor doesn't prescribe that medication.

The offending drug should be stopped without any delay and the symptomatic treatment should be started and the patient should be monitored continuously. Healthcare professionals should maintain the record of a medication history of the patient to identify any drug allergy so that it can be avoided in the future and in case of any ADR it should be reported. The patient should be counseled regarding the ADR and what preventive measures and cures should be taken in case of future drug administration.

Acknowledgement: We would like to thank Shri Devendra Das Ji Maharaj and Shri
Mahant Indiresh Hospital for supporting us in case monitoring and reporting. We would also like to thank our mentor Dr, Madhulata Rana for the support.

\section{Conflict of Interest: None}

\section{Source of Funding: None}

\section{REFERENCES}

1. Van Bambeke F, Tulkens PM. Safety profile of the respiratory fluoroquinolone moxifloxacin: comparison with other fluoroquinolones and other antibacterial classes. Drug Safety 2009; 32:359-78.

2. Ball P. Quinolone generations: natural history or natural selection? J Antimicrob Chemother 2000; 46 (suppl T1):17-24.

3. Sárközyv G. Quinolones: A class of antimicrobial agents. Vet Med Czech. 2001; 46:257-74.

4. López Blanca, Natalia; Andreu, Inmaculada; Jaén Torres, J Maria, Hypersensitivity reactions to quinolones, Current Opinion in Allergy and Clinical Immunology: August 2011-Volume 11-Issue 4-p 285-291, doi: 10.1097/ACI.0b013e3283489bc3.

5. APICELLA MICHAEL, C. ALLEN JAMES, A Physiologic Differentiation between Delayed and Immediate Hypersensitivity, The Journal of Clinical Investigation Volume 48; 1969, Page 250-259.

6. Manfredi M, Severino M, Testi $S$, et al. Detection of specific IgE to quinolones. $\mathrm{J}$ Allergy Clin Immunol 2004; 113:155-60.

7. Sachs B, Riegel S, Seebeck J, et al. Fluoroquinolone-associated anaphylaxis in spontaneous adverse drug reaction reports in Germany: differences in reporting rates between individual fluoroquinolones and occurrence after first-ever use. Drug Safety 2006; 29:1087

8. Venturini Diaz M, Lobera Labairu T, del Pozo Gil MD, et al. In vivo diagnostic tests in adverse reactions to quinolones. J Investig Allergol Clin Immunol 2007; 17:393-8.

9. Seitz CS, Brocker EB, Trautmann A. Diagnostic testing in suspected fluoroquinolone hypersensitivity. Clin Exp Allerg 2009; 39:1738-45.

10. Aranda A, Mayorga C, Ariza A, et al. In vitro evaluation of IgE-mediated hypersensitivity reactions to quinolones. Allergy 2011; 66:24754.

11. Blanca-Lopez N, Ariza A, Dona I, et al. Hypersensitivity reactions to 
fluoroquinolones: analysis of the factors involved. Clin Exp Allergy 2013; 43:560-7.

12. Kulthanan, K.; Chularojanamontri, L.; Manapajon, A.; Dhana, N.; Jongjarearnprasert, K. Cutaneous adverse reactions to fluoroquinolones. Dermatitis 2011, 22, 155160.

13. Mendes-Bastos, P.; Carvalho, R.; Cunha, D.; Cardoso, J. Ciprofloxacin: An uncommon drug reaction to a commonly used drug. Korean J. Intern. Med. 2014, 29, 263-264.

14. Cozzani, E.; Chinazzo, C.; Burlando, M.; Romagnoli, M.; Parodi, A. Ciprofloxacin as a trigger for bullous pemphigoid: The second case in the literature. Am. J. Ther. 2016, 23, e1202-e1204.

15. Iliyas, M.; Reddy, M.; Devi, U. Ciprofloxacininduced generalised non-bullous fixed drug eruption. BMJ Case Rep. 2018.

16. Sobrino-García, M.; Gómez-Cardeñosa, A.; Moreno-Rodilla, E.; Muñoz-Bellido, F.J.; Lázaro-Sastre, M.; Dávila, I. A case report of fixed drug eruption caused by several drugs because of cross-reactivity and cosensitization. Contact Dermat. 2019, 80, 5657.

17. D. Fernández Tahia, et al, Hypersensitivity to fluoroquinolones, The expression of basophil activation markers depends on the clinical entity and the culprit fluoroquinolone, Medicine (2016) 95:23, Page 1-7.

18. García-Rubio I, Martínez-Cócera C, Santos Macadán S, Rodríguez-Jiménez B, VázquezCortés S. Hypersensitivity reactions to metronidazole. Allergol Immunopathol (Madr).2006; 34(2):70-2.

19. Asensio Sánchez, Dávila I, Moreno E, Laffond E, Macías E, RuizA, et al. Anaphylaxis due to metronidazole with positive skinprick test. J Investig Allergol Clin Immunol. 2008; 18(2):138-9.

20. García-Rubio Isabel, et al, Hypersensitivity reactions to metronidazole, Allergol Immunopathol (Madr) Mar-Apr 2006; 34(2):70-2.

21. Fernández-Jorge B, Goday Buján J, Fernández-Torres R, Rodríguez-Lojo R, Fonseca E. Concomitant allergic contact dermatitis from diphenhydramine and metronidazole. Contact Dermatitis. 2008; 59(2):115-6.

22. Prieto A, De Barrio M, Infante S, Torres A, Rubio M, Olalde S. Recurrent fixed drug eruption due to metronidazole elicited by patch test with tinidazole. Contact Dermatitis.2005; 53(3):169-70.
23. Kurohara ML, Kwong FK, Lebherz TB, Klaustermeyer WB. Metronidazole hypersensitivity and oral desensitization. J Allergy Clin Immunol. 1991:88:279-80.

24. Aníbarro B, Fontela JL. Immediate rhinoconjunctivitis induced by metamizole and metronidazole. Ann Allergy Asthma Immunol. 1997; 78:345-6.

25. Bedi RS. Metronidazole-induced asthma. Indian J Chest Dis Allied Sci. 1991; 33(4):213-5.

26. Chen KT, Twu SJ, Chang HJ, Lin RS. Outbreak of Stevens-Johnson syndrome/ toxic epidermal necrolysis associated with mebendazole and metronidazole use among Filipino laborers in Taiwan. Am J Public Health. 2003; 93(3):489-92.

27. Watsky K. Acute generalized exanthematous pustulosis induced by metronidazole: the role of patch testing. Arch Dermatol. 1999; 135:93-4.

28. Weart CW, Hyman LC. Serum sickness associated with metronidazole. South Med J. 1983; 76(3):410-1.

29. Aruanno A, Parrinello G, Buonomo A, Rizzi A, Nucera E, Metronidazole Hypersensitivity in a Patient with Angioedema and Widespread Rash, J Investig Allergol Clin Immunol 2020; Vol. 30(5): 371-373.

30. Fabrizio Franceschini, et al, Mechanisms of hypersensitivity reactions induced by drugs Pub med, Acta Biomed. 2019; 90(Suppl 3): 44-51.

31. Celik, G.E.; Pichler, W.J.; Adkinson, N.F. Drug allergy. In Middleton's Allergy: Principles and Practice, 8th ed.; Adkinson, N.F., Bochner, B.S., Burks, A.W., Busse, W.W., Holgate, S.T., Lemanske, R.F., O'Hehir, R.E., Eds.; Elsevier Saunders: Philadelphia, PA, USA, 2014; Volume 2, pp. 1280-1282.

32. Baldo Brian A, Pham Nghia H, Mechanisms of Hypersensitivity, Pub med, Drug Allergy. 2013 May 3: 37-90.

33. Mohan Harsh, Textbook of Pathology, The Health Sciences and Publishers, Edition 7 Page: 58-61.

How to cite this article: Bahuguna R, Joshi D, Rana M. Ciprofloxacin and metronidazole allergy- a case report. International Journal of Science \& Healthcare Research. 2021; 6(4): 8792. DOI: https://doi.org/10.52403/ijshr. 20211014 